\title{
PRIORITIES FOR COASTAL ECOSYSTEM SCIENCE-A REVIEW
}

\author{
By Donald F. Boesch and Edward R. Urban, Jr.
}

$\mathrm{C}$ OASTAL ECOSYSTEMS are under increasing pressure as a result of expanding use of coastal areas for habitation, commerce, and recreation. These areas, including estuaries, bays, shorelines, and continental shelves are used intensively and receive the byproducts of coastal and inland human activities via direct deposition, input from rivers, and atmospheric deposition. Chemical pollutants (e.g., DDT, mercury, tributyl tin, and nutrients) that arrive from these sources harm marine organisms, damage coastal ecosystems, and, ultimately, affect humans. Ecosystems can also be damaged when the abundance of a species is altered by removing and introducing organisms and by changing the physical environment.

Scientists have studied coastal systems for the past century and have significantly improved our fundamental knowledge about how coastal ecosystems function, the life histories of organisms that comprise ecosystems, and human effects on ecosystems. In many cases, past research was not focused on solving environmental problems, but knowledge gained has been useful for decreasing environmental impacts and managing living resources. Despite the significant investment in fundamental and applied coastal science over the past century, important scientific and management challenges remain or have only recently emerged. Concern is shifting from assessing the risks from single factors and managing on a parameter-by-parameter basis to the risks involving multiple factors (e.g., combined effects of chemical contaminants and low oxygen) and to indirect. cascading. and scale-dependent effects that require an ecosystem approach. These complex, large-scale problems pose different challenges to coastal environmental policy, management, and science than the problems now subject to direct regulation, such as

Donald F. Boesch. Center for Environmental and Estuarine Studies, University of Maryland. PO Box 775. Cambridge. Maryland 21613. USA: Edward R. Urban, Jr.. Ocean Studies Board. HA-470 National Research Council. Washington, DC 20418, USA. point-source discharges, coastal land use, direct habitat destruction, and oil spills. To meet these new challenges, scientific approaches need to include studies of basic processes as well as studies directed to specific, management-relevant issues. (For a recent assessment of the use of science in coastal policymaking, see NRC, 1995.)

Federal approaches to coordinating coastal science have evolved over the past decade. Previously, interagency cooperation related to coastal science primarily took the form of informal interactions among individual program managers. During the Bush Administration, a few high-priority areas, including global change and coastal science, were targeted for the development of focused interagency research activities under the auspices of the Federal Coordinating Council on Science, Engineering, and Technology (FCCSET). Coastal activities were the responsibility of the Subcommittee on U.S. Coastal Ocean Science (SUSCOS). SUSCOS inventoried federal coastal ocean science programs and developed a framework for federal research priorities. Federal agencies spent an estimated $\$ 227$ million to conduct or sponsor scientific activities in coastal areas in FY1993 (NSTC, 1995). The Clinton Administration developed a new structure, replacing FCCSET, that attempts to coordinate all science activities among government agencies. The new organization, the National Science and Technology Council (NSTC), set up nine committees. One is the Committee on Environment and Natural Resources Research (CENR), which is developing national research and development strategies on issues such as global change, biodiversity and ecosystem dynamics, resource use and management, air quality, toxic substances, natural disasters, and water resources and aquatic environments, as well as social and economic sciences, technology, and risk assessment. Coastal ocean issues are combined with watershed issues in CENR's Subcommittee on Water Resources and Coastal and Marine Environments Research. This committee, originally cochaired by Douglas Hall (Deputy Administrator of
Despite the

significant investment

in fundamental and

applied coastal sci-

ence over the past

century, important

scientific and

management

challenges remain or

have only recently

emerged. 
the National Oceanic and Atmospheric Administration) and Robert Perciasepe (Assistant Administrator for Water in the Environmental Protection Agency) is responsible for developing a national research and development strategy and implementation plan for aquatic environments. This "Water Subcommittee" is using a recently completed assessment of freshwater research priorities (Naiman et al., 1995) and an interagency framework for coastal science developed by SUSCOS (NSTC, 1995).

The Water Subcommittee requested that the Ocean Studies Board of the National Research Council (NRC) form a committee to assess the priority issues faced by managers of coastal ecosystems and the agencies that fund coastal science. The Water Subcommittee requested that the assessment consider previous NRC studies, using Setting a New Course for U.S. Coastal Ocean Science (NSTC, 1995) as a framework and focusing on broad themes developed by the Water Subcommittee: 1) integrated monitoring, 2) water availability and flow, 3) water quality and aquatic ecosystem functions, 4) ecological restoration and rehabilitation, and 5) predictive systems management. The NRC appointed a committee of coastal scientists to respond to the request. The report of the NRC Committee to Identify High-Priority Science to Meet National Coastal Needs (NRC, 1994) is summarized below.

The committee began with its own identification of important coastal issues based on the seriousness of the problem involved, the opportunity for significant progress in scientific understanding or application, and the potential for linkage of science across the land-sea interface. Eutrophication, habitat modification, hydrologic and hydrodynamic disruption, exploitation of resources, toxic effects, introduction of nonindigenous species, global climate change and variability, shoreline erosion and hazardous storms, and pathogens and toxins affecting human health were identified as factors posing significant threats to the integrity of coastal ecosystems. The committee then made recommendations for priority research to address the nine issues it identified, in the context of the five themes developed by the Water Subcommittee as described below.

Integrated monitoring. Federal agencies should promote and support the development and implementation of observation systems that focus on interactions among atmosphere, land, and water dynamics at relevant time and space scales. The committee recommended the following: 1) measuring diffuse inputs entering the coastal zone from rivers and the atmosphere; 2) developing better indicators of biological status and processes for ecosystem monitoring; 3 ) deploying improved in situ and remote-sensing systems to monitor processes spanning a wide range of spatial and temporal scales; 4) linking local, regional, and na- tional monitoring to improve their comparability and utility; and 5) improving monitoring management systems by designing monitoring that is appropriate to the problem being addressed and integrated more fully with management decision making, research, and modeling.

Water availability and flow. Federal agencies should promote and support the improved understanding of the natural patterns and processes associated with hydrological flow and develop methodologies to assess and predict cumulative effects of watershed alteration. The committee recommended the following: 1) studying the coupling of watershed hydrology and material fluxes through application of remote sensing and improved geographic information data bases, research on land-use management, and investigation of material fluxes and controls of nitrogen and phosphorus export; 2) developing atmosphere-watershed coastal models to synthesize findings, guide research, and serve as management tools; and 3 ) increasing understanding of physical forcing processes from the head of estuaries to the edge of the continental shelf.

Water quality and aquatic ecosystem functions. Federal agencies should promote and support the development of a predictive understanding of the linkages between water quality and aquatic ecosystem functions. The committee recommended the following: 1) relating nutrient flux to ecosystem dynamics, 2) conducting strategic assessments of toxic effects; 3 ) investigating the role of sediment in coastal ecosystems; 4) relating resource use to ecosystem sustainability; 5) assessing the impact of multiple stressors on a variety of scales; and 6) promoting comparative coastal ecosystem science.

Ecological restoration and rehabilitation. Federal agencies should promote and support the improved understanding of baseline and altered aquatic systems and develop restoration methodologies and evaluation criteria. The committee recommended the following: 1) determining effects of habitat loss and degradation on biodiversity and productivity; 2) advancing restoration science and engineering; and 3) improving the remediation of toxic contamination through studies of the fate and transport of toxic materials mobilized from sediments and of in situ and other remediation technologies.

Predictive systems management. Federal agencies should promote and support the development of understanding, tools, methods, and models necessary to support water systems and ecosystem management for competing demands. The committee recommended the following: 1) implementing observation and prediction systems founded on near real-time measurement of ecosystem properties and processes; 2) developing and employing ecosystem models as management tools; 3) advancing adaptive ecosystem management; and 4) 
stimulating interactions between science and management by supporting exchanges of scientists and managers, and training in science and technology transfer for scientists and managers.

U.S. federal agencies and the national scientific community have an obligation to contribute to the advancement and application of coastal science worldwide. This obligation stems from U.S. leadership in coastal research and education and from international commitments. United States involvement in international coastal science also provides opportunities to gain comparative knowledge that can be applied to maintain healthy coastal ecosystems in the United States. The NRC committee recommended that the Water Subcommittee identify mechanisms to promote intellectual exchange and scientific coordination with relevant international coastal science efforts, such as the Land-Ocean Interactions in the Coastal Zone (LOICZ) initiative and the Global Ocean Observing System (GOOS).

The goals of the Water Subcommittee focus on the management of water resources and the maintenance of healthy coastal ecosystems. Additional coastal science priorities are being considered by other CENR subcommittees and NSTC committees, including those on global climate change; biodiversity and ecosystem dynamics; resource use and management; natural disasters; social and economic sciences; national security; health, safety, and food; and fundamental science. Although the integrated consideration of freshwater resources and coastal marine environments under the aegis of the Water Subcommittee encourages the timely development of a larger view of interacting ecosystems across the land-ocean boundary, there remains the need to plan and coordinate scientific activities, involving coastal waters, across all relevant committees and subcommittees within NSTC. The NRC committee recommended that the Water Subcommittee interact with these other NSTC components to understand how they will treat watershed and coastal research issues and to develop comprehensive coastal research activities across the NSTC. The NSTC has addressed the need for a cross-committee look at ecosystem research priorities by establishing an Ecosystem Work Group. This group reviewed ecosystem priorities across all the subcommittees and made recommendations for integrated priorities, including a recommendation to develop a mechanism to implement a coordinated interagency ecological monitoring and research network.

Addressing the issues identified by the NRC committee will require unprecedented coordination and cooperation among state and federal agencies, in conjunction with the scientific community. New approaches such as comparisons among coastal systems, will be needed to make efficient use of coastal research resources. The NRC committee recommended that an integrated scientific framework be established for coastal science that 1) facilitates systematic application of research results from individual studies in specific coastal regions that address resource management problems occurring in other regions, 2) encourages cooperative interagency activities, and 3) is based on a strong commitment to fundamental, investigator-initiated science. Many research programs and applications that have been planned and initiated in the past 15 years are still appropriate today and should form a basis for new interagency cooperative activities.

\section{References}

Naiman, R.J., J.J. Magnuson, D.M. McKnight and J.A. Stanford, 1995: The Freshwater Imperative: A Research Agenda. Island Press, Washington, D.C.

National Research Council (NRC), 1994: Priorities for Coastal Ecosystem Science. National Academy Press, Washington, D.C.

National Research Council (NRC), 1995: Science, Policy, and the Coast: Improving Decisionmaking. National Academy Press, Washington, D.C.

National Science and Technology Council (NSTC), 1995: Setting a New Course for U.S. Coastal Ocean Science. National Science and Technology Council. Washington, D.C. $\square$
. . comparisons

among coastal

systems, will be

needed to make

efficient use of

coastal research

resources. 